\title{
Association of serum levels of lipid and its novel constituents with the different stages of esophageal carcinoma Yutao Diao ${ }^{\dagger 1,2}$, Hao $\mathrm{Li}^{\dagger 3}$, Huiqing $\mathrm{Li}^{* 2}$, Yingzhi Zhou ${ }^{4}$, Qing Ma², Yan Wang ${ }^{1}$ and Dong $\mathrm{Li}^{5}$
}

\author{
Address: ${ }^{1}$ College of Public Health, Shandong University, Jinan, PR China, ${ }^{2}$ Institute of Basic Medicine of Shandong Academy of Medical Sciences, \\ Jinan, PR China, ${ }^{3}$ Department of Hematology, Tumor Center of Qilu Hospital, Shandong University, Jinan, PR China, ${ }^{4}$ College of Economics, \\ Shandong University, Jinan, PR China and ${ }^{5}$ People's Hospital, Feicheng County, Shandong Province, PR China \\ Email: Yutao Diao - dyutium@sina.com; Hao Li - haoli611@yahoo.com.cn; Huiqing Li* - huiqing4192@yahoo.com.cn; \\ Yingzhi Zhou - yzzhou@sdu.edu.cn; Qing Ma - shuangtian123@163.com; Yan Wang - swallowshm@yahoo.com.cn; \\ Dong Li - lidong19630714@126.com \\ * Corresponding author †Equal contributors
}

Published: 29 October 2009

Lipids in Health and Disease 2009, 8:48 doi:10.1186/1476-5IIX-8-48

This article is available from: http://www.lipidworld.com/content/8/l/48

(C) 2009 Diao et al; licensee BioMed Central Ltd.

This is an Open Access article distributed under the terms of the Creative Commons Attribution License (http://creativecommons.org/licenses/by/2.0), which permits unrestricted use, distribution, and reproduction in any medium, provided the original work is properly cited.
Received: 28 September 2009

Accepted: 29 October 2009

\begin{abstract}
Background: The aim of the study was to evaluate the association of immunoglobulin $G$ type of autoantibodies to oxidized low-density lipoprotein (oxLDL-lgG) and oxLDL-lgM with the progression of esophageal squamous cell carcinoma (ESSC).

Methods: Residents from Feicheng, China aged 40 to 69 years were screened for esophageal lesions in a screening program conducted during the period of January 2008 to December 2006. There were 33 controls with normal esophageal squamous epithelium cells, 37 patients with basal cell hyperplasia, 47 with esophageal squamous cell dysplasia, and 43 with ESCC. All the participants were diagnosed by biopsy and histopathological examination. Adiponectin, oxidized low-density lipoprotein (oxLDL), autoantibodies against oxLDL (oxLDL-ab), OxLDL-lgG, and OxLDL-lgM were determined by enzyme linked immunosorbent assay (ELISA). Total cholesterol, High-density lipoprotein (HDL), triglyceride, serum albumin, and blood pressure were co-estimated. Analysis of covariance for lipid levels was used to control the influence of covariates.
\end{abstract}

Results: The level of oxLDL-lgM increased gradually along with esophageal carcinoma progression. The oxLDL-IgM levels in the ESCC group were the highest after possible covariates were controlled. Binary logistic regression showed that oxLDL-lgM had a positive correlation with the development of esophageal carcinoma, while oxLDL and oxLDL-ab had a negative correlation with ESSC. No significant association between the levels of oxLDL-lgG and adiponectin and the different stages of ESSC was observed.

Conclusion: The present study shows that the decreased oxLDL and oxLDL-ab and the elevated oxLDL-IgM serum levels may relate to the development and progression of ESSC. 


\section{Background}

Conflicting data have been reported on the association between low serum cholesterol levels and the risk for cancer mortality. Some observational studies show that low serum cholesterol is associated with an increased risk of cancer mortality [1-4], but some failed to establish a connection [5-8].

A meta-analysis of 18 cohort studies showed a significantly increased risk of total cancer death in men (but not in women) with total cholesterol concentrations less than $160 \mathrm{mg} / \mathrm{dL}(4.15 \mathrm{mmol} / \mathrm{L})$ compared with those with levels at 160-199 mg/dL (4.15-5.16 mmol/L) [9].

There may be a causal link between low cholesterol and cancer. But it is possible that the associations between low blood cholesterol concentrations and risks of cancer are the consequences of confounding factors $[3,4]$. In addition, it is also possible that the associations follow a cause-and-effect relationship, possibly the preclinical cancer effect on cholesterol levels [10-12]. For instance, mortality from liver and colon cancer is significantly associated with a very low cholesterol level without any evidence of a preclinical cholesterol-lowering effect [13].

Although the mechanism is unclear, this phenomenon indicates that blood lipid levels are related to the development and progression of tumors. However, expression levels of serum cholesterol may not be the unique representative of the lipid markers.

The significance of lipid and its novel constituents such as adiponectin, immunoglobulin $G$ and $M$ types of autoantibodies to oxidized low-density lipoprotein (oxLDL-lgG and oxLDL-lgM) has been previously established in relation to cardiovascular disease $[14,15]$. Oxidized LDL, as an autoantigen, plays a crucial role in atherogenic lesion formation $[16,17]$. Serum oxLDL as well as the autoantibodies against it (oxLDL-ab) may be considered as biomarkers of lipid peroxidation [18]. There are two antibody isotypes to oxLDL, namely, the IgG and IgM autoantibodies. Although still controversial, overall evidence supports the notion that IgG autoantibodies to OxLDL are associated with pro-atherogenic properties and IgM autoantibodies to OxLDL with anti-atherogenic properties [19-21].

Meanwhile, studies also showed that adiponectin, oxLDL$\lg \mathrm{G}$, and oxLDL-lgM may play a role in various types of malignancies [15]. Petridou, et al. studied the relationship between adiponectin and childhood myeloblastic leukemia [22], while Wang, et al. proposed that oxLDL autoantibody might be related to esophageal cancer [23]. Furthermore, it has been found in animal models that a high level of lipid peroxidation is closely associated with carcinogenesis [24,25].

It can be assumed that lipid and its novel constituents(oxLDL-ab, oxLDL-lgG and oxLDL-lgM) may also be associated with different stages in carcinogenesis proceeding. Pathological and epidemiological studies suggest that the malignant transformation of human esophageal mucosa is a progressive process that starts from normal epithelium to basal cell hyperplasia, followed by dysplasia, or carcinoma in situ, and finally to invasive esophageal squamous cell carcinoma (ESCC). Dysplasia, out of the 4 progressive stages is considered as an important precancerous lesion of esophageal cancer [26-28].

In this context, we carried out a program for the screening of esophageal lesions by endoscopic staining with $1.2 \%$ iodine solution in Feicheng, China between January 2004 and December 2006. Through the program, we obtained samples of 4 groups respectively having normal epithelium, basal cell hyperplasia, dysplasia, or carcinoma in situ, and ESCC. The foundation of these samples pressed us to establish the relationship of the serum levels of lipidrelated constituents to these different lesions and carcinoma of the esophagus, especially the levels of oxLDL-lgG or/and oxLDL-lgM to the different stages in the progression of ESSC.

\section{Methods}

\section{Study subjects}

Between January 2004 and December 2006, we screened all the residents aged 40 to 69 in Feicheng, China, who agreed to participate in the program. We excluded those with liver diseases, diabetes, or cardiovascular diseases including coronary heart disease, angina pectoris, myocardial infarction, cardiac arrhythmia, and heart failure diagnosed by general medical check up, electrocardiogram, and abdomen supersonic inspection. All participants took part in the endoscopic staining with $1.2 \%$ iodine solution. Biopsies were taken from a non-staining area of the mucosa, and the samples underwent two separate pathologic evaluations carried out by two pathologists. Based on the examinations, the subjects were divided into four groups: the control group with normal esophageal squamous epithelium cells, the basal cell hyperplasia group, the esophageal squamous cell dysplasia group, and the ESCC group. The subjects in this study were randomly selected from the four groups. There were 33 subjects with normal esophageal squamous epithelium cells in the control group; 37 patients had basal cell hyperplasia, 47 had esophageal squamous cell dysplasia, and 43 had ESCC. Informed consent was obtained from all the subjects. The study protocol was approved by the local ethics committee. 


\section{Measurements}

An epidemiologic survey of the characteristics of the subjects such as name, gender, age, and smoking and drinking habits was conducted using a questionnaire. The body weight and height of each subject were measured, and the body mass index (BMI) was calculated as weight in kilograms divided by height in square meters. Blood pressure was measured by mercury sphygmomanometer. Hypertension was defined as having systolic pressure (SBP) $\geq$ $140 \mathrm{mmHg}$ and/or diastolic pressure (DBP) $\geq 90 \mathrm{mmHg}$, or those who were already undergoing medications for hypertension.

\section{Blood Sampling and Biochemical Analysis}

Venous blood samples were taken in the morning after an overnight fast of at least $12 \mathrm{hr}$. Plasma and serum were separated according to the different requirements. The specimens were kept frozen at $-40^{\circ} \mathrm{C}$ until assayed. High density lipoprotein (HDL), total cholesterol (TC), and triglyceride (TG) levels were determined by enzymatic techniques. Low density lipoprotein (LDL) was calculated by the Friedewald formula [LDL = TC - HDL - TG/5]. Serum albumin was determined by the bromocresol green method. All the assays were performed under the instructions supplied by the corresponding manufacturers.

\section{Determination of serum ADP, oxLDL, oxLDL-ab, oxLDL- IgG, and oxLDL-lgM}

An enzyme-linked immunosorbent assay(ELISA) for ADP, oxLDL, oxLDL-ab, oxLDL-lgG, and oxLDL-lgM was performed with ADP, oxLDL, oxLDL-ab, oxLDL-lgG and oxLDL-lgM ELISA kits purchased from ADL (Adliteram Diagnostic Laboratories Inc., USA). According to the manufacturer's instructions, using coated microtitration strips 96 wells, plasma was diluted 1:1 and incubated at room temperature for $1 \mathrm{hr}$ in plates precoated with ADP, oxLDL, oxLDL-ab, oxLDL-lgG, or oxLDL-lgM, respectively. After washing 3 times, the plates were incubated with horseradish peroxidase (HRP) at room temperature for $30 \mathrm{~min}$. After the removal of unbound conjugates by washing 3 times, tetramethylbenzidine (TMB) was added to the wells as a chromogenic substrate and incubated at room temperature for $10 \mathrm{~min}$ in the dark. Color development was stopped with stopping solution, and the absorbency was measured at $450 \mathrm{~nm}$ within $30 \mathrm{~min}$. ADP, oxLDL, oxLDL-ab, oxLDL-lgG, or oxLDL-lgM titers were calculated by constructing a standard curve using the standards included in the respective kits. The concentrations of ADP, oxLDL, oxLDL-ab, oxLDL-lgG, and oxLDL-lgM in the samples were quantified in biomedical units as defined by the manufacturer. The intra-assay and interassay reproducibility (indicated by coefficients of variation) of the assay were $6,5,7,6$, and 10 percent, respectively.

\section{Statistical analysis}

All statistical analyses were conducted using SPSS 15.0. The baseline characteristics were presented for quantitative data as mean (SD). The comparison in the four groups was performed using the Student's t test. The qualitative data were tested by the Chi-square test. The correlation between variables was tested using the Pearson correlation test depending on the distribution of the data. A general linear model analysis was used to control the influence of covariates when comparing the concentrations of ADP, oxLDL, oxLDL-ab, oxLDL-lgG, and oxLDL$\lg \mathrm{M}$ among the four groups. Multinomial logistic regression was applied to analyze the influential factors. Probability was significant at a level of $\leq 0.05$.

\section{Results \\ Characteristics of subjects}

The clinical and biochemical characteristics of the studied population are shown in Table 1. The variables of age, albumin, total cholesterol (TC), high-density lipoprotein (HDL), low-density lipoprotein(LDL), oxLDL, oxLDL-ab, oxLDL-lgG, and oxLDL-lgM were significantly different among the four groups. There were no significant differences in the other variables.

\section{Comparison of serum levels of ADP, oxLDL, oxLDL-ab, oxLDL-IgG, and oxLDL-IgM among the four groups}

A general linear model analysis showed that there were significant differences in the estimated marginal means of plasma oxLDL and oxLDL-lgM among the four groups. However, no significant differences were observed for ADP, oxLDL-ab and oxLDL-lgG after controlling the confounding variables i.e. age, TC, HDL, LDL, and albumin (Table 2). The results of the linear-by-linear association analysis showed that the blood serum levels of oxLDL and oxLDL-ab were decreased. However, the blood serum level of oxLDL-lgM increased with the histological spectrum of disease from normal to early invasive squamous cell carcinoma of the esophagus (Figure 1).

\section{Association of ADP, oxLDL, oxLDL-ab, oxLDL-IgG, and oxLDL-IgM with multistage development of esophageal carcinoma}

As shown in Table 3, the Odds ratio (OR) of ADP, oxLDL, oxLDL-ab, oxLDL-lgG and oxLDL-lgM were associated with the different stages in the development of esophageal carcinoma (basal cell hyperplasia, dysplasia and early invasive cancer) after adjusted for age, albumin, TC, HDL and LDL.

It is also indicated that the ORs for oxLDL-lgM were positively linked with the ESSC and dysplasia group. However, ORs for oxLDL and oxLDL-ab were negatively associated with the two groups, even if the ORs did not reached statistics significantly levels in dysplasia group. 
Table I: Characteristics of the Subjects

\begin{tabular}{|c|c|c|c|c|c|c|}
\hline variables & Control group & Basal cell hyperplasia & Dysplasia group & ESSC group & $F / x^{2}$ & $p$ \\
\hline Age, years & $49 \pm 8$ & $53 \pm 8$ & $56 \pm 7$ & $58 \pm 7$ & 10.286 & $0.000 *$ \\
\hline Sex, M/F & $18 / 15$ & $24 / 13$ & $28 / 19$ & $28 / 15$ & 1.155 & 0.764 \\
\hline Hypertension, Y/N & $18 / 15$ & $20 / 17$ & $18 / 29$ & $21 / 22$ & 2.893 & 0.408 \\
\hline $\mathrm{BMI}, \mathrm{kg} / \mathrm{m}^{2}$ & $22.90 \pm 2.72$ & $22.93 \pm 2.90$ & $22.06 \pm 2.60$ & $21.73 \pm 3.31$ & 1.728 & 0.164 \\
\hline $\mathrm{SBP}, \mathrm{mmHg}$ & $132 \pm 26$ & $132 \pm 19$ & $|3| \pm 20$ & $127 \pm 17$ & 0.549 & 0.649 \\
\hline $\mathrm{DBP}, \mathrm{mmHg}$ & $86 \pm 14$ & $85 \pm 12$ & $82 \pm 12$ & $78 \pm 14$ & 2.325 & 0.077 \\
\hline Smokers, Y/N & $15 / 18$ & $17 / 20$ & $24 / 23$ & $24 / 19$ & 1.119 & 0.773 \\
\hline Drinkers, $\mathrm{Y} / \mathrm{N}$ & $15 / 18$ & $24 / 13$ & $24 / 23$ & $23 / 20$ & 2.890 & 0.409 \\
\hline Albumin, g/L & $38 \pm 3$ & $44 \pm 8$ & $40 \pm 6$ & $38 \pm 8$ & 8.161 & $0.000 *$ \\
\hline $\mathrm{TC}, \mathrm{mmol} / \mathrm{L}$ & $3.45 \pm 1.09$ & $3.63 \pm 0.83$ & $3.62 \pm 0.80$ & $2.54 \pm 0.96$ & 13.684 & $0.000 *$ \\
\hline $\mathrm{TG}, \mathrm{mmol} / \mathrm{L}$ & $0.61 \pm 0.43$ & $0.68 \pm 0.46$ & $0.57 \pm 0.40$ & $0.50 \pm 0.32$ & 1.481 & 0.222 \\
\hline LDL, mmol/L & $0.12 \pm 0.33$ & $0.08 \pm 0.27$ & $0.09 \pm 0.28$ & $0.23 \pm 0.15$ & 11.439 & $0.000 *$ \\
\hline $\mathrm{HDL}, \mathrm{mmol} / \mathrm{L}$ & $0.77 \pm 0.22$ & $0.91 \pm 0.22$ & $0.85 \pm 0.21$ & $0.67 \pm 0.24$ & 8.667 & $0.000 *$ \\
\hline ADP, ng/L & $10.27 \pm 10.98$ & $11.18 \pm 13.10$ & $14.33 \pm 13.38$ & $12.98 \pm 11.79$ & 0.850 & 0.469 \\
\hline oxLDL, ng/L & $33.66 \pm 11.54$ & $27.40 \pm 10.33$ & $30.27 \pm 11.83$ & $23.94 \pm 10.72$ & 5.264 & $0.002^{*}$ \\
\hline oxLDL-ab, U/ml & $38.33 \pm 26.44$ & $38.97 \pm 21.38$ & $32.52 \pm 12.87$ & $26.59 \pm 7.88$ & 4.210 & $0.007 *$ \\
\hline oxLDL-lgG, ng/ml & $12.54 \pm 4.67$ & $18.14 \pm 10.47$ & $16.56 \pm 8.42$ & $10.23 \pm 6.78$ & 8.453 & $0.000^{*}$ \\
\hline oxLDL-IgM, ng/ml & $20.56 \pm 5.99$ & $23.27 \pm 6.17$ & $24.63 \pm 6.35$ & $26.60 \pm 5.88$ & 6.402 & $0.000 *$ \\
\hline
\end{tabular}

$* p<0.05$; Abbreviations: ESSC, esophageal squamous cell carcinoma; MBI, body mass index; SBP, 0 systolic blood pressure; DBP, diastolic blood pressure; TC, total cholesterol; TG, triglyceride; HDL, High-density lipoprotein; LDL, Low-density lipoprotein; ADP, adiponectin; oxLDL, oxidized low-density lipoprotein; oxLDL-lgG, immunoglobulin G type of autoantibodies to oxidized low-density lipoprotein; oxLDL-lgM, immunoglobulin M type of autoantibodies to oxidized low-density lipoprotein.

\section{Discussion}

In the present study, there was a significantly lower serum level of TC and HDL-c. Moreover, there were significantly higher serum levels of LDL-c in the ESSC group than those in the control group, which is similar to those previously found in the literature $[1-5,10]$.

Plasma adiponectin levels were found to be lower in patients with many cancers, especially in upper gastric cancers, compared with those in the normal controls. It is inversely correlated with tumor size, depth of invasion, and tumor TNM stage, suggesting a potential role of adi- ponectin in the progression of gastric cancer [29]. There was no similar information for esophageal carcinoma. In the present study, we did not find plasma adiponectin levels to be related to the multistage development of esophageal cancer.

The predominant isotype of oxLDL antibodies isolated either from serum (free antibodies) or from precipitated soluble immune complexes (antigen-associated antibodies) is IgG, which is of the subclasses 1 and 3 [30,31]. A positive correlation between the levels of oxLDL-lgG antibodies and the different endpoints considered as evidence

Table 2: Estimated Marginal Means and UNIANOVA Test of Apinectin, oxLDL, oxLDL-ab, oxLDL-IgG, and oxLDL-IgM in Four Groups ${ }^{\mathbf{a}}$

\begin{tabular}{lccccc}
\hline & ADP & oxLDL & oxLDL-ab & oxLDL-IgG & oxLDL-IgM \\
\hline ESSC group & $11.699 \pm 2.715$ & $25.436 \pm 1.951$ & $28.123 \pm 3.124$ & $13.378 \pm 1.214$ & $26.519 \pm 1.073$ \\
Dysplasia group & $13.980 \pm 1.867$ & $30.130 \pm 1.675$ & $32.101 \pm 2.681$ & $15.645 \pm 1.065$ & $24.380 \pm 0.921$ \\
Basal cell hyperplasia group & $11.903 \pm 2.202$ & $26.629 \pm 1.976$ & $37.367 \pm 3.164$ & $15.553 \pm 1.257$ & $22.989 \pm 1.087$ \\
Control group & $11.614 \pm 2.363$ & $32.790 \pm 2.120$ & $38.742 \pm 3.395$ & $12.656 \pm 1.349$ & $21.329 \pm 1.166$ \\
$F$ test & 0.332 & 2.739 & 2.098 & 1.445 & 3.503 \\
$P$ & 0.802 & 0.045 & 0.103 & 0.232 & 0.017 \\
Trend test $\mathrm{t}^{\mathrm{b}}$ & 1.518 & 9.421 & 10.412 & 2.789 & 17.137 \\
$P$ & 0.218 & 0.002 & 0.001 & 0.095 & 0.000
\end{tabular}

Abbreviations: TC, total cholesterol; TG, triglyceride; ADP, adiponectin; HDL, High-density lipoprotein; LDL, Low-density lipoprotein; oxLDL, oxidized low-density lipoprotein; oxLDL-lgG, immunoglobulin G type of autoantibodies to oxidized low-density lipoprotein; oxLDL-lgM, immunoglobulin $M$ type of autoantibodies to oxidized low-density lipoprotein.

a Means (SE) for estimated marginal means; Covariates appearing in the model are evaluated at the following values: $T G=3.296 \mathrm{I}, \mathrm{LDL}=2.23 \mathrm{I}$, $\mathrm{HDL}=0.7992$, Albumin $=40.2234$, age $=54.55$.

b Linear --by --linear association test. 

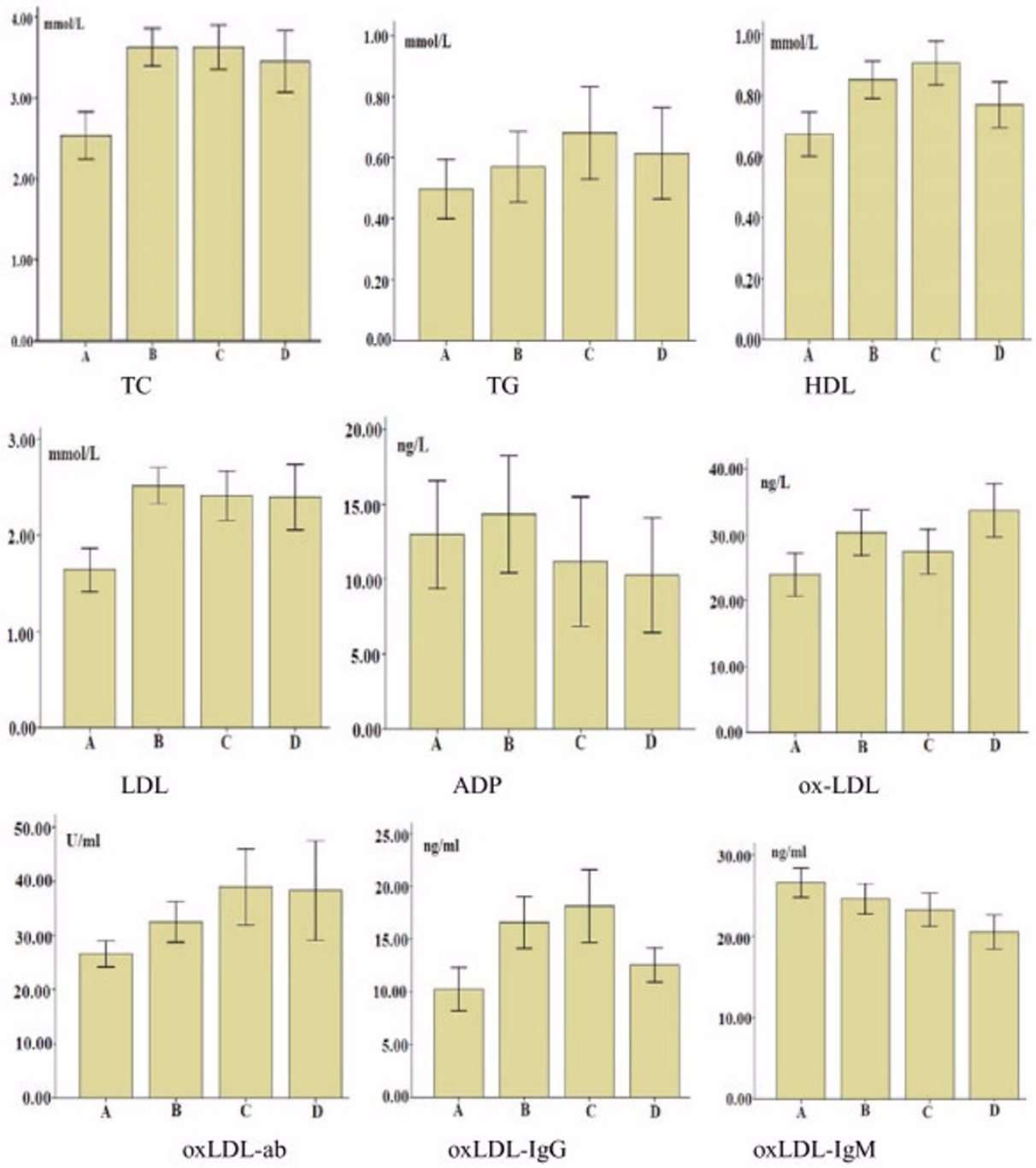

\section{Figure I}

Mean concentrations of serum biochemical indicators in group. Mean concentrations of serum biochemical indicators in groups of ESSC (A), dysplasia (B), basal cell hyperplasia (C), and normal control (D). Adp, HDL, LDL, oxLDL, oxLDL-ab, oxLDL-IgG, oxLDL-IgM, TC, and TG respectively represent adiponectin, high-density lipoprotein, low-density lipoprotein, oxidized low-density lipoprotein, total antibodies to oxidized low density lipoprotein, oxidized low-density lipoprotein IgG, oxidized low-density lipoprotein lgM, total cholesterol, and total triglyceride.

of atherosclerotic vascular disease has been reported by many studies [32,33]. In addition, the protective role of IgM oxLDL antibodies has been proposed in human cardiovascular diseases $[25,34]$. However, other studies have failed to support these findings [35-37].

Recent research works show that the antibody against oxLDL serum levels in patients with hepatocellular carcinoma [38] and squamous cell carcinoma of the esophagus [17] is lower than that in the normal controls. However, the isotypes of oxLDL-lgG and oxLDL-lgM were not separately detected in these reports.
The main finding of the present study is the descending trends of plasma oxLDL, oxLDL-ab, and oxLDL-lgG levels and the elevated trends of plasma oxLDL-lgM levels along with the series of histological spectrum of disease from normal to early invasive squamous cell carcinoma of the esophagus.

In recent years, there has been a growing body of evidence that states the excessive lipid peroxidation products including oxLDL and anti-oxLDL autoantibodies, which are reflected in the indicators of oxidative stress in vivo, may play a key role in cancer development $[39,40]$. Lipid 
Table 3: Multinomial Logistic Analysis for the Multistage Development of Esophageal Carcinoma

\begin{tabular}{lllllll}
\hline & \multicolumn{2}{l}{ Unadjusted OR \& 95\%CL } & & \multicolumn{3}{l}{ Adjusted OR \& 95\%CL* } \\
\cline { 2 - 7 } variables & ESSC & dysplasia & Basal cell hyperplasia & ESSC & dysplasia & Basal cell hyperplasia \\
\hline ADP & $1.02(0.98-1.06)$ & $1.03(0.99-1.07)$ & $1.01(0.97-1.05)$ & $1.02(0.97-1.06)$ & $1.03(0.99-1.07)$ & $1.01(0.96-1.05)$ \\
oxLDL & $0.92(0.88-0.94)$ & $0.98(0.94-1.01)$ & $0.96(0.92-1.00)$ & $0.94(0.89-0.99)$ & $0.97(0.93-1.01)$ & $0.95(0.91-0.99)$ \\
oxLDL-ab & $0.93(0.88-0.97)$ & $0.98(0.96-1.01)$ & $1.00(0.98-1.02)$ & $0.96(0.91-1.00)$ & $0.98(0.95-1.01)$ & $1.00(0.98-1.02)$ \\
oxLDL-IgG & $0.94(0.87-1.01)$ & $1.07(1.01-1.14)$ & $1.09(1.03-1.16)$ & $1.03(0.94-1.13)$ & $1.07(0.99-1.16)$ & $1.07(0.99-1.15)$ \\
oxLDL-IgM & $1.21(1.10-1.33)$ & $1.15(1.05-1.27)$ & $1.11(1.01-1.22)$ & $1.18(1.06-1.31)$ & $1.11(1.01-1.23)$ & $1.08(0.98-1.20)$
\end{tabular}

Abbreviations: TC, total cholesterol; TG, triglyceride; ADP, adiponectin; HDL, High-density lipoprotein; LDL, Low-density lipoprotein; oxLDL, oxidized low-density lipoprotein; oxLDL-lgG, immunoglobulin G type of autoantibodies to oxidized low-density lipoprotein; oxLDL-lgM, immunoglobulin $M$ type of autoantibodies to oxidized low-density lipoprotein.

*:adjusted for age, albumin, TC, HDL, and LDL.

peroxidation metabolites damage DNA and can seriously inhibit DNA repair capacity through their direct interaction with repair proteins [41]. Furthermore, they influence the intracellular redox equilibrium, affecting several crucial signal transduction pathways [42]. The oxLDL, shown either in vivo or in vitro, has a cytotoxic effect against endothelial cells and smooth muscle cells of the arterial wall, as well as a chemotactic activity for circulating monocytes [21]. Low serum levels of the oxLDL antibody can lead to uncontrolled cell proliferation and to the reduction of apoptosis, contributing to the induction of carcinogenesis. oxLDL increases the activity of $\mathrm{C}$ protein kinase (PKC), which is a serin-treonin kinase that acts on the cytoplasmatic transduction of the mytogenic signal, induced from GF [43]. The PKC exerts its action supporting the activity of P21 ras protein involved in the pathogenesis of many humans tumors [44]. oxLDL is also able to induce the production and delivery of other growth factors (GF) such as that derived from platelets (PDGF), probably through interleukin 1 and TNF- $\beta$. It has been demonstrated that PDGF, codified from c-sys oncogenes, seems to be involved in the uncontrolled growth of many tumors [45]. The anti-oxLDL autoantibodies may be activated through all these different ways to induce the development and progression of esophageal cancer.

In this study, all subjects were diagnosed by histopathology, which ruled out the possibility of the misclassification error. In the experimental determination of the indicators, we used less than 10 percent of the coefficient of variation as quality control. In order to avoid the occurrence of collinearity, a covariance analysis was used in the analysis. The variance inflation factor(VIF) of ADP, oxLDL, oxLDL-ab, oxLDL-lgG, and oxLDL-lgM were $0.232,0.880,0.910,0.867$, and 0.984 , respectively. Therefore, the main results of this study were neither biased nor by chance.

In the present study, we found that the descending levels of oxLDL and oxLDL-ab may negatively related to the dif- ferent stages of the development of esophageal cancer while the elevated levels of oxLDL-lgM has a positive potence, which is contrary in the case of their relations to cardiovascular and cerebrovascular diseases revealed in previous literature.

However, the isotype antibodies against oxLDL serum levels in cancer cannot be defined in universal terms. Furthermore, large clinical sample studies are required in order to elucidate whether oxLDL as well as oxLDL antibodies play a causative or merely consequential role in the cancer process, and to designate a novel strategy for cancer prevention and therapy.

\section{Conclusion}

This study shows that the decreasing oxLDL and oxLDL-ab negatively relate to the different stages of the development of esophageal squamous cell carcinoma while the elevated oxLDL-lgM serum levels may positively relate to the development and progression of ESSC. This conclusion may be helpful for cancer prevention and therapy.

\section{Abbreviations}

TC: total cholesterol; TG: triglyceride; ADP: adiponectin; HDL: High-density lipoprotein; LDL: Low-density lipoprotein; oxLDL: oxidized low-density lipoprotein; oxLDLlgG: immunoglobulin $G$ type of autoantibodies to oxidized low-density lipoprotein; oxLDL-lgM: immunoglobulin $\mathrm{M}$ type of autoantibodies to oxidized low-density lipoprotein; ESCC: esophageal squamous cell carcinoma; oxLDL-ab: antibodies to oxidized low density lipoprotein

\section{Competing interests}

The authors declare that they have no competing interests.

\section{Authors' contributions}

Members listed below made their respective contributions to this manuscript. 
Professor HQL designed the skeleton of this study, supervised the epidemiologic survey of the characteristics of the subjects, performed the statistical analysis and drafted the manuscript. HL, YTD, YZZ, QM and YW carried out the immunoassays in addition to biochemical analysis, whereas HL and YTD also participated in the compiling of this manuscript. DL engaged in the screening of esophageal lesions, inspected the subject(including some inpatients)enrolled in this study. All authors read and approved the final manuscript.

\section{Acknowledgements}

This study were supported by the Projects of National Natural Science Foundation of China (No.3057I60I \& No.30600258), the doctor fund projects of 2006 in Shandong Province (No. 2006BS0306I) and the special fund for innovative projects in the post-doctoral funding of 2007 (No. $200,702,034)$ in Shandong Province, China.

\section{References}

I. Schuit AJ, Van Dijk CEM, Dekker JM, Schouten EG, Kok FJ: Inverse association between serum total cholesterol and cancer mortality in Dutch civil servants. Am J Epidemiol 1993, 137:966-976.

2. Wannamethee G, Shaper AG, Whincup PH, Walker M: Low serum total cholesterol concentrations and mortality in middle aged British men. BMJ I995, 3 I I:409-4I3.

3. D'Agostino RB, Belanger AJ, Kannel WB, Higgins M: Role of smoking in the U-shaped relation of cholesterol to mortality in men. The Framingham Study. Am J Epidemiol 1995, | 41:822-827.

4. Eichholzer M, Stähelin HB, Gutzwiller F, Lüdin E, Bernasconi F: Association of low plasma cholesterol with mortality for cancer at various sites in men: $17-y$ follow-up of the prospective Basel study. Am J Clin Nutr 2000, 71:569-574.

5. Iribarren C, Reed DM, Burchfield CM, Dwyer JH: Serum total cholesterol and mortality. JAMA 1995, 273:1926-1932.

6. Smith GD, Shipley MJ, Marmot MG, Rose G: Plasma cholesterol concentration and mortality. The Whitehall Study. JAMA 1992, 267:70-76.

7. Dyer AR, Stamler J, Paul O, Shekelle RB, Schoenberger JA, Berkson DM, Lepper M, Collette P, Shekelle S, Lindberg HA: Serum cholesterol and risk of death from cancer and other causes in three Chicago epidemiological studies. J Chronic Dis I98I, 34:249-260.

8. Baptiste MS, Nasca PC, Doyle JT, Rothenberg RR, MacCubbin PA, Mettlin C, Metzger BB, Carlton KA: Cholesterol and cancer in a population of male civil service workers. Int J Epidemiol 1992 , 21:16-22.

9. Jacobs D, Blackburn H, Higgins M, Reed D, Iso H, McMillan G, Neaton J, Nelson J, Potter J, Rifkind B, et al.: Report of the conference on low blood cholesterol: mortality associations. Circulation 1992, 86: 1046-1060.

10. Pekkanen J, Nissinen A, Punsar S, Karvonen MJ: Short- and longterm association of serum cholesterol with mortality: the 25-year follow-up of the Finnish cohorts of the Seven Countries Study. Am J Epidemiol 1992, 135: I25I-1258.

II. Wannamethee G, Shaper AG, Whincup PH, Walker M: Low serum total cholesterol concentrations and mortality in middleaged British men. BMJ I995, 3 I I:409-4I3.

12. Sharp SJ, Pocock SJ: Time trends in serum cholesterol before cancer death. Epidemiology 1997, 8: /32-136.

13. Song YM, Sung JH, Kim JS: Which Cholesterol Level Is Related to the Lowest Mortality in a opulation with Low Mean Cholesterol Level: A 6.4-Year Follow-up Study of 482,472 Korean Men. Am J Epidemiol 2000, I 5 1:739-747.

14. Virella G, Carter RE, Saad A, Crosswell EG, Game BA: DCCT/EDIC Study Group and Maria F. Lopes-Virella. Distribution of IgM and IgG antibodies to oxidized LDL in immune complexes isolated from patients with type I diabetes and its relationship with nephropathy. Clinical Immunology 2008, 127:394-400.
15. Bar D, Williams CJ, Neuwirth AK, Mantzoros CS: Adiponectin in relation to malignancies: a review of existing basic research and clinical evidence. Am J Clin Nutr 2007, 86(suppl):858s-866s.

16. Itabe $\mathrm{H}$, Yamamoto $\mathrm{H}$, Imanaka $\mathrm{T}$, Shimamura K, Uchiyama H, Kimura J, Sanaka T, Hata Y, Takano T: Sensitive detection of oxidatively modified low density lipoprotein using a monoclonal antibody. J Lipid Res 1996, 37:45-53.

17. Uchida K: 4-hydroxy-2-nonenal: a product and mediator of oxidative stress. Prog Lipid Res 2003, 42:3।8-343.

18. Nishi K, Itabe H, Uno M, Kitazato KT, Horiguchi H, Shinno K, Nagahiro S: Oxidized LDL in carotid plaques and plasma associates with plaque instability. Arterioscler Thromb Vasc Biol 2002, 22:1649-1654.

19. Gounopoulos P, Merki E, Hansen LF, Choi SH, Tsimikas S: Antibodies to oxidized low density lipoprotein: epidemiological studies and potential clinical applications in cardiovascular disease. Minerva Cardioangiol 2007, 55:82 I-837.

20. Ohashi $\mathrm{R}, \mathrm{Mu} \mathrm{H}$, Yao Q, Chen $\mathrm{C}$ : Atherosclerosis: immunopathogenesis and immunotherapy. Med Sci Monit 2004, 10:255-260.

2I. Karvonen J, Päivänsalo M, Kesäniemi YA, Hörkkö S: Immunoglobulin M type of autoantibodies to oxidized low-density lipoprotein has an inverse relation to carotid artery atherosclerosis. Circulation 2003, 108:2107-2112.

22. Petridou E, Mantzoros CS, Dessypris N, Trichopoulos D, et al.: Adiponectin in relation to childhood myeloblastic leukaemia. British J Cancer 2006, 94:156-160.

23. Wang $Y$, Li H, Diao Y, Li H, Zhang $Y$, Yin C, Cui $Y$, Ma Q, Fang $X$, Zhou Y, Yang Y: Relationship between oxidized LDL antibodies and different stages of esophageal carcinoma. Arch Med Res 2008, 39:760-767.

24. Chung FL, Nath RG, Ocando J, Nishikawa A, Zhang L: Deoxyguanosine adducts of t-4-hydroxy-2-nonenal are endogenous DNA lesions in rodents and humans: detection and potential sources. Cancer Res 2000, 60:I507-I5II.

25. ánchez-Pérez Y, Carrasco-Legleu C, García-Cuellar C, Pérez-Carreón J, Hernández-García S, Salcido-Neyoy M, Alemán-Lazarini L, Villa-Treviño S: Oxidative stress in carcinogenesis. Correlation between lipid peroxidation and induction of preneoplastic lesions in rat hepatocarcinogenesis. Cancer Lett 2005, 217:25-32.

26. Yang CS: Research on esophageal cancer in China: a review. Cancer Res 1980, 40:2633-2644.

27. Qiu SL, Yang GR: Precursor lesions of esophageal cancer in high-risk populations in Henan Province, China. Cancer 1988, 62:55I-557.

28. Yang GR, Oiu SL: Endoscopic surveys in high-risk populations for esophageal cancer in China with special reference to precursors of esophageal cancer. Endoscopy 1987, 19:91-95.

29. Kelesidis I, Kelesidis T, Mantzoros CS: Adiponectin and cancer: a systematic review. British Journal of Cancer 2006, 94:I22I-I 225.

30. Virella G, Koskinen S, Krings G, Onorato JM, Thorpe SR, LopesVirella M: Immunochemical characterization of purified human oxidized low-density lipoprotein antibodies. Clin Immunol 2000, 95:I35-I44.

31. Virella G, Lopes-Virella MF: Lipoprotein autoantibodies: measurement and significance. Clin Diag Lab Immunol 2003, 10:499-505.

32. Erkkilä AT, Närvänen $O$, Lehto $S$, Uusitupa MIJ, Ylä-Herttuala $S$ : Autoantibodies against oxidized low-density lipoprotein and cardiolipin in patients with coronary heart disease. Arterioscl. Thromb Vasc Biol 2000, 20:204-209.

33. Saad AF, Virella G, Chassereau C, Boackle RJ, Lopes-Virella MF: OxLDL immune complexes activate complement and induce cytokine production by MonoMac 6 cells and human macrophages. J Lipid Res 2006, 47:1975-1983.

34. Tsimikas S, Witztum JL, Miller ER, Sasiela WJ, Szarek M, Olsson AG, Schwartz GG: High-dose atorvastatin reduces total plasma levels of oxidized phospholipids and immune complexes present on apolipoprotein B-100 in patients with acute coronary syndromes in the MIRACL trial. Circulation 2004, I I0:|406-|4|2.

35. Boullier A, Hamon M, Walters-Laporte E, Martin-Nizart F, Mackereel R, Fruchart JC, Bertrand M, Duriez P: Detection of autoantibodies against oxidized low-density lipoproteins and of IgG- 
bound low density lipoproteins in patients with coronary artery disease. Clin Chim Acta 1995, 238:I-10.

36. Hulthe J, Wiklund O, Hurt-Camejo E, Bondjers G: Antibodies to oxidized LDL in relation to carotid atherosclerosis, cell adhesion molecules, and phospholipase A(2). Arterioscl Thromb Vasc Biol 200I, 21:269-274.

37. Fredrikson GN, Hedblad B, Berglund G, Alm R, Nilsson JA, Schiopu A, Shah PK, Nilsson J, Nilsson J: Association between IgM against an aldehyde-modified peptide in apolipoprotein B-100 and progression of carotid disease. Stroke 2007, 38: I495-1500.

38. Ozer Nk, Boscoboinik D, Azzi A: New roles of low density lipoproteins and vitamin $E$ in the pathogenesis of atherosclerosis. Biochem Mol Biol Intern 1995, 35: I I7-I 24.

39. Guyton KZ, Kensler TW: Oxidative mechanisms in carcinogenesis. Br Med Bull 1993, 49:48I-483.

40. Wiseman H, Halliwell B: Damage to DNA by reactive oxygen and nitrogen species; role in inflammatory disease and progression to cancer. Biochem J 1996, 313:17-19.

41. Brown NS, Bicknell R: Hypoxia and oxidative stress in breast cancer. Oxidative stress: its effects on the growth, metastatic potential and response to therapy of breast cancer. Breast Cancer Res 200I, 3:323-327.

42. Motta M, Pistone G, Franzone AM, Romeo MA, Di Mauro S, Giugno I, Ruello P, Malaguarnera M, Malaguarnera M: Antibodies against oxLDL serum levels in patients with hepatocellular carcinoma. Panminerva Med 2003, 45:69-73.

43. Kelly K, Cochran BH, Stiles CD, Leder P: Cell specific regulation in normal and neoplastic cells. Adv Cancer Res 1990, 56: I-48.

44. Downward J, Graves JD, Warne PH: Stimulation of P2I (MD30) ras upon T-cell activation. Nature 1990, 346:719-723.

45. Oberhammaer F, Burch W, Parzefall W, Breit P, Erber E, Stadler M, Schulte-Hermann R: Effect of transforming growth factor $\beta$ on cell death of cultured rat hepatocytes. Cancer Res 1991, 5 I:2478-2485.

Publish with Biomed Central and every scientist can read your work free of charge

"BioMed Central will be the most significant development for disseminating the results of biomedical research in our lifetime. "

Sir Paul Nurse, Cancer Research UK

Your research papers will be:

- available free of charge to the entire biomedical community

- peer reviewed and published immediately upon acceptance

- cited in PubMed and archived on PubMed Central

- yours - you keep the copyright
BioMedcentral 